\title{
Effectiveness of Professional Learning Communities in Ghanaian Basic Schools through the Lenses of Socio-Cultural Theory
}

\author{
Dandy George Dampson (Corresponding author) \\ Department of Educational Foundations \\ University of Education, P.O. Box 25, Winneba, Ghana \\ E-mail: dgdampson@gmail.com
}

Received: October 21, $2021 \quad$ Accepted: November 23, 2021

Published: December 1, 2021

doi:10.5296/jei.v7i2.19114 URL: https://doi.org/10.5296/jei.v7i2.19114

\begin{abstract}
This study employed the explanatory sequential mixed-methods design to assess the effectiveness of PLCs in Ghanaian basic schools. Using proportional stratified random sampling technique, the study selected 650 respondents (400 teachers and 250 headteachers) from the basic schools in five regions of Ghana for the quantitative phase of the study. Subsequently, 30 teachers and 10 headteachers from these schools were sampled purposely for the qualitative phase of the study. An adapted version of PLACA-R (6-dimensions; $\alpha$ $=$.84-.92) from Olivier and Hipp (2010) was used to collect quantitative data whilst researchers designed an interview guide was used to gather qualitative data. The quantitative data were analyzed using descriptive (means and standard deviation) statistics whilst the qualitative data were analyzed thematically. The study established the level of PLC activities in the basic schools is low on all the 6 dimensions of the scale except shared and supportive leadership. A good number of the basic schools have never held any PLC meetings since the curriculum was introduced. Schools that observed PLC meetings often ignore the delivery methods in the PLC manual. The study also found that female teachers practice PLC more than male teachers. The study further established that age, educational qualification and years of experience have a significant impact on the practice of PLC. The study concluded that teachers and headteachers in the basic schools lack knowledge and pedagogical skills about PLCs and their roles in the professional development of the teachers. It was recommended that the participation of PLCs by teachers and Headteachers should be used as one of the tools for teacher promotion.
\end{abstract}


Keywords: Professional learning communities, Socio-cultural theory, Dialogue, Teachers

\section{Introduction}

Globally, two factors continue to put enormous pressure on teachers to constantly improve (Serin, 2017). Society expects schools to produce students with the complex intellectual skills required by the "knowledge society," but these are lacking in students trained by schools (McLaughlin \& Talbert, 2006). Again, societal dissatisfaction with the unequal student outcomes that have characterized schools for generations, with advantaged students outperforming students with fewer resources to support their learning (Nixon, 2013). Teachers' knowledge, abilities, and practice norms have received increasing attention as a result of this inequality. Given this, stakeholders have issued a clarion cry for all children to learn to high standards and have access to high-quality training (Olajuwon, 2017).

Teachers' ability to deliver the kinds of classroom experiences needed to increase all students' learning and achievement is highlighted by the demand to modify and improve the schools (Kini \& Podolsky, 2016). Teachers need to master new types of instruction and pedagogy, as well as a fundamental rethinking of learning, for this to happen. McLaughlin and Talbert (2006) posit that the $21^{\text {st }}$ Century new knowledge society expects cognitive skills, but not enough teachers can structure education to emphasize them. It appears there are not enough teachers who can effectively work with students from a wide range of cultural, ethnic, and socioeconomic backgrounds. However, there is a consensus among scholars that not enough teachers are willing to relinquish the role of classroom "sage" and knowledge transmitters to take on a new role that focuses on helping students solve problems and develop their lifelong skills (Dole, Bloom, \& Kowalske, 2016; Mahmood, \& Iqbal, 2018). These issues confronting education necessitate a significant investment in teacher training. However, there appears to be widespread agreement that teacher education falls short of adequately preparing personnel as compared to other professions such as medicine and engineering to deal with the exigencies of the century (Schwille, Dembélé, \& Schubert, 2007). Given this, in-service teachers often have to resort to workshops and seminars to improve and sharpen their pedagogical skills. It is accepted that externally driven professional development efforts are more likely to have episodic effects on education reform because they tend to be pasted onto existing instructional and institutional arrangements with little attention paid to issues of sustaining improvement or deepening practice (Tyack \& Cuban, 1996). Again, without opportunities for instructors to locate external knowledge in their classrooms or school contexts, external knowledge such as workshops and seminars will not be enough to satisfy society's aims (McLaughlin \& Talbert, 2002) and are insufficient in developing instructional professionalism and accountability for all students' learning (Louis \& Marks, 1998). Meanwhile, enhanced student learning is dependent on teacher learning; yet, the ultimate payout of teachers' learning opportunities is contingent on teachers' willingness to collaborate to improve education for their students. To this end, professional learning communities have become paramount for teachers in the $21^{\text {st }}$ Century.

Even though there are several definitions of PLC, they all depict a professional community in which teachers collaborate to reflect on their practice, examine the evidence about the 
relationship between practice and student outcomes, and make changes that improve teaching and learning for the students in their classes (McLaughlin \& Talbert, 2006). PLC, therefore, stands for shared mission, vision, and values; collective inquiry; collaborative teams; an orientation toward action and a readiness to experiment; dedication to continuous development; and an emphasis on results (DuFour \& Eaker,1998). Teachers, it is arguable, can benefit from the perspectives and practices of different educational systems and cultures to update their thinking, knowledge, and abilities to education (Huang, 2018). According to Edge, Mejias, Odeck, Ogolla, Sannoh, and Suswele (2008), teachers develop a more positive attitude toward global issues and gain access to a broader range of teaching strategies when they engage in school, districts, regional, national and international networks of professional learning. As intimated by Stoll (2011), PLC is a mutually-reflecting and growth-oriented group of people with a collaborative, reflective, and growth-oriented approach to examining and learning more about their profession to improve pupils' learning.

This study is grounded through the lenses of socio-cultural theory. Learning and knowing as social involvement, according to Wenger (1998), has four components: community, practice, meaning, and identity. Members of professional groups, in particular, learn techniques by exchanging work artifacts and contesting the meaning of their work. Simultaneously, they rectify their learning and expertise by building new cultural artifacts, allowing members of professional groups to execute better activities and negotiate meaning in new ways (Huang, 2018). In this era, the constructivist view of learning and social learning theories that stress learning through involvement in practice in social settings can be linked to teacher learning in PLCs theoretically (Jones, Gardner, Robertson, \& Robert, 2013). As indicated by Meiers and Buckley (2009), PLCs provide a non-confrontational avenue to receive feedback wherein teachers can compare their strategies with others and learn via modelling. Student performance data can act as a source of diagnostic information about students' progress but also as a way to monitor whether improvements might be associated with the implementation of new teaching practices. Finally, feedback could also be a design feature of professional development programmes such that teachers learn about the content and pedagogical content, in addition to gaining feedback about their progress in these areas. In this study sociocultural theory is used to refer to society's crucial role in individual development. The relationship between developing people and the culture in which they live is emphasized in this study. As human learning is primarily a social process, according to sociocultural theory teachers who are the main participants in this study cannot be solely trained in the university or the training colleges. It is important to note that teacher development extends beyond the classroom to the larger community. Whenever teachers find themselves in their professional groups, they must submerge themselves in the culture of the environment. Proponents of the theory believe that parents, caregivers, peers, and the culture at large are responsible for developing higher-order functions.

Despite the established role of PLC in teacher development, available evidence suggests that the mere inclusion of PLC in policy documents does not guarantee its practice at the school level, district or regional levels (Vajarintarangoon, Bunkanan, Deelon, Poldech, \& Thauyngam, 2019). Even in areas where PLCs are organized, extant literature remains 
inconclusive on the level of implementation of PLCs. Using literature and documentary analysis, Hairon and Dimmock (2012) established that even though policy documents have always made provisions for the implementation of PLCs for more than a decade in Singapore, its practice has been slow thereby affecting the teachers' pedagogical practices in the classroom. A recent collaborative study conducted by Hairon and Tan (2016) on PLCs in Singapore and Shangai revealed that despite being integrated into centralised education systems, there are still substantial variances in the implementation of PLCs in the two jurisdictions. Their study found potential problems in implementing PLCs such as heavy teacher workloads, difficulties in the understanding and implementation of PLCs, and hierarchical work structures. In Iceland, Svanbjörnsdóttir, Macdonald and Frímannsson (2016) reported from an action study revealing hints of a nascent collaborative structure among some teams, as well as a lack of peer input with teachers citing difficulty in putting their newly acquired professionalism into practice. PLCs are still uncommon in New Zealand and little is known about how such communities might be developed and integrated (Thorton \& Cherrington, 2018). The uncommonness was blamed on factors such as clear membership and effective induction for new members; a shared focus, commitment and research orientation; clarity of roles including leadership roles; opportunities for dialogue and deprivatisation of practice and stimulus of new ideas. In South Africa, Botha (2012) reports that school leaders do not encourage teachers to share educational practices and collaborate to create better school cultures. Essentially, many South African teachers work in isolation. It is, therefore, easy to speculate that the seclusion of teachers from PLCs might render them susceptible and unable to meet the prerequisites of effective teaching.

\subsection{The Context}

In the Ghanaian context, the phenomenon of PLC was only formalized in the Basic School curriculum in 2017 when the standard-based curriculum was introduced. The dearth of literature from the Ghanaian perspective makes it difficult to ascertain whether PLCs are being effectively organized to help teachers to improve their professional practice as stipulated. Over the last few decades, the forms of PLC and the scope of their application have evolved (Huang, 2018). The concept and practice of PLC appear to have been introduced and promoted in the United States in the form of whole-school PLCs or subject departments (McLaughlin \& Talbert, 1993). PLC later became a globally shared concept and a common practice for school improvement in general, and teacher in-service professional learning in particular. The form of PLC has evolved in tandem with the growing popularity of PLCs in schools (Lee, Zhang, \& Yin, 2011; McNicholl, Childs, \& Burn, 2013). The evidence of learning in networked PLCs appears promising globally; however, it appears limited in Africa in general (Botha, 2012), and Ghana in particular. Meanwhile, extant literature highlights the indispensable role of PLC in teachers' continuous development (Jones, Stall, \& Yarbrough, 2013; Capili-Balbalin, 2017). It is this realization among curriculum developers in Ghana that prompted the inclusion of PLC in the new Standard-based Curriculum (SBC) for basic schools in Ghana.

The SBC, which was introduced in September 2019 stipulated that two hour in every week should be devoted to Professional Learning Communities (PLC) to improve the performance 
of the teachers and further boost the academic achievement of the students. It, however, appears that since the introduction of the curriculum, little or no empirical studies have been conducted to ascertain the effectiveness of the PLCs in the basic schools. Informal conversations with some teachers in the regions selected for the study appear to suggest that most schools in Ghana either implement PLCs wrongly from the stipulated tenets or do not implement the PLCs at all. The informal conversations with the teachers in the regions seem to suggest that most teachers are often seen in town during the time scheduled for PLC meetings whilst those who even attend the meetings do not exhibit any tendency to willingly share their classroom challenges to guide discussions in PLCs. The lack of empirical studies on the effectiveness of PLCs in Ghanaian Basic Schools presupposes that the Ministry of Education and its subsidiary agencies such as the Ghana Education Service and NaCCA may not have data to guide policy implementation.

Besides the paucity of literature on the subject matter in Ghana, most studies on the phenomenon across the world have often used literature review (Botha, 2012; Hairon \& Dimmock, 2016), the quantitative method (Chena, Leeb, Lin \& Zhang, 2016; Burns, Naughton, Preast, Wang, Gordon, Robb, \& Smith, 2017) with few employing the mixed-method paradigm (Buttram \& Farley-Ripple, 2016; Heggen, Raaen \& Thorsen, 2018). There are, therefore, contextual and methodological gaps in the literature. This study sought to fill the identified gaps by assessing the level of implementation of PLCs in Ghanaian Basic Schools by answering the following research questions:

(1) What is the relative strength of practices within each PLC dimension in the Basic Schools in the Five Regions of Ghana?

(2) Is there a significant difference in the practice of PLC between male and female teachers in the Basic Schools in the Five Regions in Ghana?

(3) Do Socio-Demographic Characteristics of the teachers in the Five Selected Regions affect their Practice of PLCs?

\section{Methodological Considerations}

\subsection{Research Design}

This study was grounded in the pragmatist research philosophy. It, therefore, adopted the mixed method paradigm. Specifically, the study employed the concurrent-parallel design (Quan-qual). This design was deemed to be the most suited since the researchers wanted to triangulate the different methodologies by comparing quantitative and qualitative findings directly for corroboration and validation (Onwuegbuzie \& Johnson, 2006).

\subsection{Sample and Sampling Procedures}

In the collection of the quantitative data, the researcher sampled 650 respondents made of 400 teachers and 250 headteachers from a population of 40,000 through the proportionate-stratified random sampling technique from the five regions in Ghana, namely-Greater Accra, Ashanti, Western, Northern, Eastern. The sampling size was selected based on Krejcie and Morgan's (1970) table for determining sampling size. Krejcie and 


\section{Macrothink}

Morgan indicate that it is appropriate to sample a minimum of 380 respondents for the study. To ensure the validity of the study, the research increased the sample size to 450 . Subsequently, 15 teachers and 10 headteachers were sampled purposively for the qualitative phase of the study.

\subsection{Data Collection Instrument}

An adapted version of PLACA-R five-point Likert-scale questionnaire (6-dimensions; 45 items; $\alpha=.84-.92)$ from Olivier and Hipp (2010) with factored subscales $(n=625)$ : Shared and Supportive Leadership (.92); Shared Values and Vision (.91); Collective Learning and Application (.91); Shared Personal Practice (.88); Supportive Conditions-Relationships (.84); Supportive Conditions-Structures (.89) and an overall Cronbach Alpha Reliability Coefficients of .89 was used to collect quantitative data. Even though the original instrument contains 52 items, the researcher deleted seven items that did not align with the context in which the study was conducted based on results from the pilot test conducted. Other items were also modified to suit the researcher's context. The qualitative data was, however, collected using a researcher designed interview guide based on the quantitative results.

\subsection{Statistics and Data Analysis}

The data analysis was done in two phases. First, with the aid of the Statistical Package for the Social Sciences (SPSS) software, the quantitative data were analyzed using descriptive (Means and Standard Deviations) and inferential statistics (Independent Samples t-test and ANOVA). In the second stage, the researchers evaluated the field notes, transcribed the audio interview data, and categorized them into themes using Miles and Huberman's methodology for thematic analysis (1994). Thus, the qualitative data was analysed thematically.

\section{Results and Discussion}

This section discussed the demographic characteristics of the teachers and headteachers who were involved in the study. The demographic characteristics were first discussed whilst the main results were discussed subsequently. 
Table 1. Demographic characteristics of respondents

\begin{tabular}{|c|c|c|c|}
\hline \multirow{2}{*}{ Variable } & \multirow{2}{*}{ Subscale } & Teachers & Headteachers \\
\hline & & N (\%) & N (\%) \\
\hline \multirow{2}{*}{ Gender } & Male & $226(56.5)$ & $143(57.2)$ \\
\hline & Female & $174(43.5)$ & $107(42.8)$ \\
\hline \multirow{7}{*}{ Age } & $25-30$ & $21(5.3)$ & $9(3.6)$ \\
\hline & $31-35$ & $98(24.5)$ & $23(9.2)$ \\
\hline & $36-40$ & $97(24.3)$ & $29(11.6)$ \\
\hline & $41-45$ & $78(19.5)$ & $41(16.4)$ \\
\hline & $46-50$ & $52(13.0)$ & $45(18.0)$ \\
\hline & $51-55$ & $36(9.0)$ & $72(28.8)$ \\
\hline & $56-60$ & $18(4.5)$ & $31(12.4)$ \\
\hline \multirow{3}{*}{ Educational Qualification } & Diploma & $327(81.8)$ & $169(67.6)$ \\
\hline & First Degree & $65(16.2)$ & $53(21.2)$ \\
\hline & Masters & $8(2.0)$ & $28(11.2)$ \\
\hline \multirow{5}{*}{ Experience (in years) } & 5 and below & $113(28.2)$ & $7(2.8)$ \\
\hline & $6-10$ & $126(31.5)$ & $30(12.0)$ \\
\hline & $11-15$ & $75(18.5)$ & $46(18.4)$ \\
\hline & $16-20$ & $46(11.5)$ & $67(26.8)$ \\
\hline & 20 and above & $40(10.0)$ & $100(40.0)$ \\
\hline \multirow{5}{*}{ Regional Distribution } & Greater Accra & $88(22.0)$ & $56(22.4)$ \\
\hline & Ashanti & $92(33.0)$ & $63(25.2)$ \\
\hline & Western & $76(19.0)$ & $48(19.2)$ \\
\hline & Northern & $60(15.0)$ & $37(14.8)$ \\
\hline & Eastern & $84((21)$. & $49(19.6)$ \\
\hline
\end{tabular}

Source: Field data, 2021.

Table 1 shows the demographic characteristics of the teachers and headteachers who were involved in the study. From the Table, it is evident that the gender pattern of the teachers (Males $=226$; females $=174$ ) is not substantially different from that of the headteachers (Males $=143$; females 107). The Ghanaian educational landscape continues to observe male dominance. However, the male dominance in the schools reinforces the need to implement PLCs to harmonize the experiences of the male and female teachers. The age brackets of the majority of the respondents presuppose that most of the teachers are relatively young. The 
youthful nature of the teachers presents an enviable platform that could be capitalized on to improve the Ghanaian education system especially when PLCs are given due recognition in the various education circle. The ages of the headteachers also underscore the need for appropriate PLCs in the schools. Coupled with this, the number of years spent in service by the teachers and the headteachers shows a blend of experienced and relatively inexperienced. The blend of youthful teachers and experienced headteachers during PLC meetings might transform most of the schools from their failing and trapped forms to improved schools (Sagor, 2011). The educational qualification of the teachers further highlights the need for PLCs. From Table 1, it is seen that 327(81.8\%) of the teachers had a Diploma, 65(16.2\%) had First Degrees whilst $8(2.0 \%)$ had Masters. This means that majority of the teachers possess the minimum qualification needed to teach at the basic schools in Ghana. However, without the necessary support in the form of in-service training, most of them might struggle to deliver in their classrooms since the data shows that only a few of the teachers return to school to upgrade their knowledge and skills. Lastly, the Table shows that the majority $(33.0 \%)$ of the teachers were sampled from the Ashanti region whilst few $(15.0 \%)$ of the teachers were sampled from the Northern region. Concerning the headteachers, Ashanti Region had the majority (25.2\%), a little bit more than Greater Accra (22.4\%), whilst Northern Region had the least (14.8\%). The regional distributions of the teachers and the headteachers reaffirm the notion that most teachers accept postings to the well-endowed regions.

3.1 What Is the Relative Strength of Practices within Each PLC Dimension in the Basic Schools in the Five Regions of Ghana?

The first research question sought to assess the relative strength of practices within each PLC dimension in the Basic Schools in the Five Regions of Ghana. From the adapted 6-point Likert-scale questionnaire, a Mean of Means and Standard Deviation was computed for the four dimensions. The results of the analysis are presented in Table 2 after which the qualitative data were used to explain the quantitative findings.

Table 2. Level of PLC implementation in Ghanaian basic schools

\begin{tabular}{|l|l|l|}
\hline Dimensional Scale & Mean & SD \\
\hline Shared and Supportive Leadership & 3.54 & .75 \\
\hline Shared Values and Vision & 2.47 & .77 \\
\hline Collective Learning and Application & 2.26 & .78 \\
\hline Shared Personal Practice & 2.25 & .89 \\
\hline Supportive Conditions_-Relationships & 2.07 & .98 \\
\hline Supportive Conditions_-Structures & 2.05 & 1.1 \\
\hline Mean of Means/Average Standard Deviation & $\mathbf{2 . 4 4}$ & $\mathbf{. 8 7}$ \\
\hline
\end{tabular}

Source: Field data, 2021. 
The results displayed in Table 2 shows that both the teachers and the headteachers engage in several PLC activities (Overall Mean $=3.24, \mathrm{SD}=.87$ ). However, the overall Mean $=2.44$ suggests that their practice is below the average mean of 2.5. This means that even though there is an effort from the teachers and the headteachers to implement PLCs in the schools, much is still needed to ensure the success of the implementation drive. Even though their overall rating was low, the data shows that on the dimensional scale of shared and supportive leadership, the respondents agreed (Mean $=3.54, \mathrm{SD}=.75$ ). Impliedly, staff members are consistently involved in discussing and making decisions about most school issues. Besides, headteachers incorporate advice from staff members to make decisions. This is very encouraging given the fact that Dampson, Havor, and Laryea (2018) had indicated that teacher participation in school decision-making had not been impressive and that most headteachers do not even entertain the idea of incorporating suggestions from the teachers in their daily decisions. From the interview, both the teachers and the headteachers concurred that they are involved in various decisions that are taken at the school level. For instance, one teacher said:

In this school, teachers'voices are heard before our head teacher takes any decision that concerns teaching and learning (Martin, a science teacher at Krofa M/A Basic School)

Another teacher maintained:

During our normal PLC meetings, the head teacher gives each teacher the fact, our see from the way things are going that we are placed at the center of major decisions that are taking in this school (Agnes, a French teacher at Nyaasemhwe Presby Primary A).

The views of the teachers were reechoed by the headteachers. For instance, one head teacher posited:

As for me, I don't believe I can single-handedly improve this school without recourse to the views of my staff. I consider their views any time I am taking any major decision about the school (Akuoko, a headteacher at Nifa R/C Primary).

Another headteacher mentioned:

I always ensure that my teachers have received all the necessary information needed for their daily activities. It there shapes our relationship during PLC sessions (Manu, the head teacher of Adubia Primary School).

These views from the teachers and the headteachers reiterate the fact that shared and supportive leadership is highly practiced in basic schools.

It is, however, evident that from Table 2 that the element of shared values and vision is not highly practiced in the schools (Mean $=2.47, \mathrm{SD}=.77$ ). This means that the teachers do not share visions for school improvement that have an undeviating focus on student learning (Olivier et al, 2009). Furthermore, the teachers and the headteachers do not set goals with a focus on students learning beyond test scores and grades. This is not surprising given the fact 
that most educational institutions in Ghana are now driven by students' grades in examinations. Teachers have therefore been left to teach for only examination purposes (Adu-Gyamfi, 2013). Teachers would therefore not have any option other than to teach or set goals that meet the demands of examination bodies or they risk the wrath of the entire society. In the interview with the teachers and headteachers, it was evident that the element of shared values and vision is underrated in the various schools. For instance, one teacher said:

Ever since I came to this school, I'm yet to school the goals of the school. As an institution, I feel the goals are set by the District Officers. How then do I help to realign the goals in such a way that I will teach beyond the textbook? (Nkansah, Asaaman L/A School)

Another teacher posited:

It is no fault of ours that we don't align our policies and programmes to fit the vision of the school. Everything in this district is centralized. Teachers have little control (Amo, a teacher at Kodieabe Presby).

A head teacher supported the views of the teachers by saying that:

In this school, we don't have any goals as a school. Every teacher sets his or her own goal. It is the district and regional office that set goals for us (Amoateng, a head teacher at Adeisu Methodist Primary).

These views from the teachers and the headteachers are show that teachers' understanding of critical issues that borders on students learning and academic achievement is not at the appreciable level since it is expected that schools set goals that align with the national aim of education.

Concerning collective learning and application, the results show that the teachers disagreed $($ Mean $=2.26, \mathrm{SD}=.78)$. This means that the teachers and headteachers do not work together to seek knowledge, skills and strategies and apply this new learning to their work neither do they engage in dialogue that reflects a respect for diverse ideas that lead to continued inquiry (Malkas, 2011). This implies that most schools depend on externally planned programmes such as district workshops or district-sponsored seminars for their continuous professional development. The continuous dependence on externally planned might not satisfy the individual needs of the teachers as well as the schools (Louis, 1994). The headteachers agreed in the interview that the only means by which they seek knowledge is through district and regionally organized in-service programmes. For instance, one head teacher said:

The budget at schools cannot run a workshop or in-service programmes for teachers in this school. We, therefore, resort to external programmes (Mante, a head teacher at Subinso).

Another head teacher concurred:

At the local level, it is difficult for schools to invite experts to help teachers to learn new crafts in their respective subject areas. The districts would not permit you. 
From this, one would not be pointless to argue that most teachers lack the necessary knowledge and skills to implement the tenets of the SBC. As such, student learning is been hampered due to the continuous dependent on external programmes.

Additionally, the Mean rating on the dimension of Shared Personal Practice was below the Standard Mean $($ Mean $=2.25, \mathrm{SD}=.89)$. This means that in the various schools, teachers are not provided with the opportunities to observe peers and offer encouragement. It is therefore not surprising to realize that most teachers do not gain feedback on their instructional practices. In essence, the schools do not offer coach and mentoring services for their teachers. There is a seeming thought among educational leaders that every graduate from a college of education possesses all the dexterity needed for the classroom venture. Meanwhile, the complex nature of the teaching profession requires that newly trained personnel are given support at the school level. Coupled with this, the changing nature of knowledge in the $21^{\text {st }}$ century requires mentorship as well as coaching (Denmark \& Podsen, 2013). The lack of coaching and mentorship could affect teaching and learning. This might partly explain why the status of education in public schools in Ghana continues to dwindle unabatedly. In the interview, the teachers did agree that the element of shared personal practice is very low in their school environment. One teacher said:

In this school, we hardly collaborate to review students' work and offer the necessary assistance to each other. Since I joined the school, I'm yet to experience something like this (Agnes, a French teacher at Nyaasemhwe Presby Primary A).

In support, another teacher had this to say:

We don't meet on regular basis to share students' work to guide overall school improvement as suggested by the new curriculum. We normally meet at the beginning of the term and the final of the term to review the entire term's activities ((Nkansah, Asaaman L/A School).

It is clear from these responses that even though the policy in the SBC has catered for PLCs, its implementation at the school level remains significantly low. It would therefore mean that the two-hour session on the timetable is always used for other activities rather than the intended.

Lastly, supportive conditions in terms of relationships (Mean $=2.07, \mathrm{SD}=.98$ ) and structures (Mean $=2.05, \mathrm{SD}=1.1$ ) were the least rated elements in the schools. It is therefore evident that most schools do not recognize and reward outstanding achievements in the schools nor do stakeholders' exhibit a sustained and unified effort to embed change into the culture of the school. Besides, the schools' schedules do not promote collective learning and shared practice. Given these circumstances, one would not be wrong to argue that most teachers in the basic schools lack the motivation needed to perform their tasks effectively.

3.2 Research Question Two: Is There Any Significant Difference in the Practice of PLC between Male and Female Teachers in the Basic Schools in the Five Regions in Ghana?

The researcher test whether there exists any significant difference in PLC between male and 


\section{Macrothink}

female teachers. Exploring all other means, the independent samples t-test was deemed appropriate for the hypothesis testing. Table 3 presents the results:

Table 3. Results of independent sample t-test comparing male and female teachers in terms of PLC

\begin{tabular}{|l|l|l|l|l|l|l|}
\hline Variable & Group & Mean & SD & t-value & Df & Sig. (2-tailed) \\
\hline Male & 369 & 53.13 & 10.837 & \multirow{2}{*}{-12.925} & 622.925 & .000 \\
\cline { 1 - 5 } Female & 256 & 68.46 & 4.870 & & & \\
\hline
\end{tabular}

Note. Significant at 0.05 level.

Source: Field data.

Table 3 indicates the results of the test of difference using the independent samples t-test. Levene's Test for Equality of Variance results indicates that equal variance among the variables (male and female teachers) was not assumed. Results from the independent sample t-test shows that there was a statistically significant difference between male teachers and female teachers, $t(124.925)=-12.925, \mathrm{p}=.000$ (2-tailed). The result suggests that male teachers engage less in PLC $(\mathrm{M}=53.13, \mathrm{SD}=10.84)$ than female teachers $(\mathrm{M}=68.46, \mathrm{SD}=$ $4.870)$ at a .05 level of significance. It implies that female teachers practice PLC more than male teachers as the results depicted. In that regard, the hypothesis indicating no difference was rejected. As indicated by Fred, Pierre, Ellen and Marjan (2020), females are found to be more enthusiastic in professional development programmes than males. As a result, they attend every programme related to their profession than their male counterparts as has been found in this study.

3.3 Research Question Three: Do Socio-Demographic Characteristics of the Teachers in the Five Selected Regions Affect Their Practice of PLCs?

In the quest of findings out how teachers' socio-demographics have impacts on their practice of PLC, the Chi-square $\left(\chi^{2}\right)$ test was used to test for associations. The results are presented in Table 4. 
Table 4. Socio-demographics (age, qualification and years of experience) on the practice of PLC

\begin{tabular}{|l|l|l|l|}
\hline Demographic Variables & Chi-square $\left(\chi^{2}\right)$ & Degree of Freedom $(\mathrm{df})$ & $\mathrm{p}$-value \\
\hline Age & 18.823 & 3 & 0.009 \\
\hline Educational Qualification & 23.228 & 3 & 0.003 \\
\hline Experience & 12.456 & 5 & 0.000 \\
\hline
\end{tabular}

Note. Significant at $\mathrm{p}=0.05$ (2-tailed).

Source: Field data.

As presented in Table 4 it is noted that there several demographic data that had an impact on teachers' practice of PLC in the five regions. These demographic data include educational qualification, age, and experience. All these factors had a significant impact on the practice of PLC. For example, age produced a significant result of $\left(\chi^{2}=18.823, \mathrm{df}=4, \mathrm{p}=0.009\right)$, educational qualification produced a significant result of $\left(\chi^{2}=23.228, \mathrm{df}=3, \mathrm{p}=0.003\right)$, and experience $\left(\chi^{2}=12.456, \mathrm{df}=5, \mathrm{p}=0.000\right)$. This means that in the design and implementation of PLC in schools, the socio-demographic characteristics of the participants should serve as a springboard to provide the needed professional development for teachers. However, it must be noted that the normal one-size fits approach in some of the professional development activities for teachers which seems to be a common practice among the Ghana Education Service and the Ministry of Education might not serve the intended purpose (Dampson et. al, 2018).

\section{Conclusions and Implications for Policy and Practice}

The study established the level of PLC activities in the basic schools is low on all the 6 dimensions of the scale except shared and supportive leadership. A good number of the basic schools have never held any PLC meetings since the curriculum was introduced. Schools that observed PLC meetings often ignore the delivery methods in the PLC manual. The study also found that female teachers practice PLC more than male teachers. Age, educational qualification and years of experience have a significant impact on the practice of PLC. The study concluded that teachers and headteachers in the basic schools in the five regions lack knowledge and pedagogical skills about PLCs and their role in the professional development of the teachers. It was recommended that the participation of PLCs by teachers and headteachers should be used as one of the tools for teacher promotion. Again, pragmatic and purposeful policies should be enshrined in the teaching standards to ensure effective participation in professional development programmes of basic school teachers and headteachers in the country. Lastly, school support and improvement officers should regularly monitor the effectiveness of PLCs on their weekly schedules to the basic schools under their supervision and report to the office of the Director of Education. 


\section{Reference}

Adu-Gyamfi, K. (2013). Lack of interest in school science among non-science students at the senior high school level. Problems of Education in the 21st Century, 53(7). https://doi.org/ $10.33225 / \mathrm{pec} / 13.53 .07$

Botha, E. M. (2012). Turning the tide: creating Professional Learning Communities (PLC) to improve teaching practice and learning in South African public schools. Africa Education Review, 9(2), 395-411. https://doi.org/10.1080/18146627.2012.722405

Burns, M. K., Naughton, M. R., Preast, J. L., Wang, Z., Gordon, R. L., Robb, V., \& Smith, M. L. (2017). Factors of professional learning community implementation and effect on student achievement. Journal of Educational and Psychological Consultation, 28(4), 394-412. https://doi.org/10.1080/10474412.2017.1385396

Buttram, J. L., \& Farley-Ripple, E. N. (2016). The role of principals in professional learning communities. Leadership and Policy in Schools, 15(2), 192-220. https://doi.org/10.1080/ 15700763.2015.1039136

Capili-Balbalin, W. (2017). The Development of Professional Learning Communities (PLCs) in the Philippines: Roles and Views of Secondary School Principals (Doctoral dissertation, University of Waikato).

Chen, P., Lee, C. D., Lin, H., \& Zhang, C. X. (2016). Factors that develop effective professional learning communities in Taiwan. Asia Pacific Journal of Education, 36(2), 248-265. https://doi.org/10.1080/02188791.2016.1148853

Cherrington, S., \& Thornton, K. (2015). The nature of professional learning communities in New Zealand early childhood education: An exploratory study. Professional Development in Education, 41(2), 310-328. https://doi.org/10.1080/19415257.2014.986817

Dampson, D. G., Havor, F. M., \& Laryea, P. (2018). Distributed Leadership an Instrument for School Improvement: The Study of Public Senior High Schools in Ghana. Journal of Education and e-Learning Research, 5(2), 79-85. https://doi.org/10.20448/journal.509.2018. 52.79 .85

Dole, S., Bloom, L., \& Kowalske, K. (2016). Transforming pedagogy: Changing perspectives from teacher-centered to learner-centered. Interdisciplinary Journal of Problem-Based Learning, 10(1), 1-15. https://doi.org/10.7771/1541-5015.1538

DuFour, R., \& Eaker, R. E. (1998). Professional learning communities at work: Best practices for enhancing student achievement. Bloomington, IN: National Educational Service.

Edge, K., Mejias, S., Odeck, A., Ogolla, N., Sannoh, B., \& Suswele, W. (2008). New partnership: Exploring the PLAN school linking programme. Research \& Development Report Year 1. London: Institute of Education, University of London.

Fred, H., Meeuwen Pierre, V., Ellen, R., \& Marjan, V. (2020). How to enhance teachers' 
professional learning by stimulating the development of professional learning communities: operationalising a comprehensive PLC concept for assessing its development in everyday educational practice. Professional Development in Education, 46(5), 751-769. https://doi.org/ $10.1080 / 19415257.2019 .1634630$

Gašević, D., Dawson, S., Rogers, T., \& Gasevic, D. (2016). Learning analytics should not promote one size fits all: The effects of instructional conditions in predicting academic success. The Internet and Higher Education, 28, 68-84. https://doi.org/10.1016/j.iheduc. 2015.10.002

Hairon, S., \& Dimmock, C. (2012). Singapore schools and professional learning communities: Teacher professional development and school leadership in an Asian hierarchical system. Educational Review, 64(4), 405-424. https://doi.org/10.1080/00131911.2011.625111

Hairon, S., \& Tan, C. (2016). Professional learning communities in Singapore and Shanghai: Implications for teacher collaboration. Compare: A Journal of Comparative and International Education, 47(1), 91-104. https://doi.org/10.1080/03057925.2016.1153408

Heggen, K., Raaen, F. D., \& Thorsen, K. E. (2018). Placement schools as professional learning communities in teacher education. European Journal of Teacher Education, 41(3), 398-413. https://doi.org/10.1080/02619768.2018.1448779

Huang, X. (2018). Teacher education in professional learning communities: Intercultural reciprocal learning in Chinese and Western Education. Palgrave: Macmillan. https://doi.org/10.1007/978-3-319-91857-0

Jones, L., Stall, G., \& Yarbrough, D. (2013). The importance of professional learning communities for school improvement. Creative Education, 4(05), 357. https://doi.org/ $10.4236 /$ ce. 2013.45052

Jones, M. G., Gardner, G. E., Robertson, L., \& Robert, S. (2013). Science professional learning communities: Beyond a singular view of teacher professional development. International Journal of Science Education, 35(10), 1756-1774. https://doi.org/10.1080/ 09500693.2013 .791957

Kini, T., \& Podolsky, A. (2016). Does teaching experience increase teacher effectiveness? A review of the research. Palo Alto: Learning Policy Institute. https://doi.org/10.54300/625.642

Krejcie, R. V., \& Morgan, D. W. (1970). Determining sample size for research activities. Educational and Psychological Measurement, 30(3), 607-610. https://doi.org/10.1177/00131 6447003000308

Lee, J. C., Zhang, Z., \& Yin, H. (2011). A multilevel analysis of the impact of a professional learning community, faculty trust in colleagues and collective efficacy on teacher commitment to students. Teaching and Teacher Education, 27(5), 820-830. https://doi.org/ 10.1016/j.tate.2011.01.006

Louis, K. S. (1994). Beyond 'managed change': Rethinking how schools improve. School Effectiveness and School Improvement, 5(1), 2-24. https://doi.org/10.1080/09243459400 
50102

Louis, K. S., \& Marks, H. M. (1998). Does professional community affect the classroom? Teachers' work and student experiences in restructuring schools. American Journal of Education, 106, 532-575. https://doi.org/10.1086/444197

Mahmood, N., \& Iqbal, Z. (2018). Challenges faced by prospective teachers during teaching Practice: Connecting theory to practice. Bulletin of Education and Research, 40(2), 113-136.

Malkas, B. (2011). The urban district leader and systemic implementation of collaborative learning communities: A mixed-method study (Unpublished Doctoral Dissertation, Sage Colleges).

McLaughlin, M., \& Talbert, J. E. (1993). Contexts that matter for teaching learning: Strategic opportunity for meeting the nation's educational goals. Center for Research on the Context of Secondary School Teaching, Office of Educational Research and Improvement (ED), Washington, DC.

McLaughlin, M., \& Talbert, J. E. (2006). Reforming districts: How districts support school reform. Seattle: Center for the Study of Teaching and Policy, University of Washington.

McNicholl, J., Childs, A., \& Burn, K. (2013). School subject departments as sites for science teachers learning pedagogical content knowledge. Teacher Development, 17(2), 155-175. https://doi.org/10.1080/13664530.2012.753941

Mireles, L. (2012). Schools of the future in Hawaii: Networked learning communities and teaching innovation (Doctoral dissertation, Pepperdine University).

Nixon, P. S. (2013). Investing in urban school leadership: creating a profile of career principals to inform indentification, recruitment, and retention in the school district of Philadelphia. (Unpublished Doctoral Dissertation, University of Pennsylvania). Retrieved from https://www.proquest.com/openview/d1f254b1ddfe02391d12bccf0c891672/1?pq-origsit $\mathrm{e}=\mathrm{gscholar} \& \mathrm{cbl}=18750$

Olajuwon, T. (2017). Transforming the educational system in Nigeria: Implication for school leaders. Journal of Educational Research and Development, 16(1), 208-220.

Olivier, D. F., Antoine, S., Cormier, R., Lewis, V., Minckler, C., \& Stadalis, M. (2009). Assessing schools as professional learning communities symposium. Annual Meeting of the Louisiana Education Research Association, Lafayette. Retrieved from http://ullresearch. pbworks.com/f/Olivier_Assessing_PLCs_Symposium_-_PLCA-R_Introduction.pdf

Olivier, D. F., Hipp, K. K., \& Huffman, J. B. (2010). Professional learning community assessment-revised. In K. K. Hipp \& J. B. Huffman (Eds.), Demystifying professional learning communities: School leadership at its best (pp. 32-35). Lanham, MD: Rowman \& Littlefield.

Onwuegbuzie, A. J., \& Johnson, R. B. (2006). The validity issue in mixed research. Research in the Schools, 13(1), 48-63. 


\section{Macrothink}

Sagor, R. (2011). The action research guidebook: A four-stage process for educators and school teams. New YorK: Corwin Press.

Schwille, J., Dembélé, M., \& Schubert, J. (2007). Global perspectives on teacher learning: Improving policy and practice. International Institute for Educational Planning (IIEP) UNESCO.

Serin, H. (2017). Developing the teaching profession: factors influencing teachers' performance. International Journal of Social Sciences \& Educational Studies, 4(2), 10-14. https://doi.org/10.23918/ijsses.v4i2sip10

Stoll, L. (2011). Leading professional learning communities. In H. Temperley \& J. Hattle (Eds.), Leadership and learning. London: Sage.

Svanbjörnsdóttir, B. M., Macdonald, A., \& Frímannsson, G. H. (2016). Teamwork in establishing a professional learning community in a new Icelandic school. Scandinavian Journal of Educational Research, 60(1), 90-109. https://doi.org/10.1080/00313831.2014. 996595

Thornton, K., \& Cherrington, S. (2018). Professional learning communities in early childhood education: A vehicle for professional growth. Professional Development in Education, 45(3), 418-432. https://doi.org/10.1080/19415257.2018.1529609

Tyack, D. B., \& Cuban, L. (1995). Tinkering toward utopia: A century of publicschool reform. Cambridge: Harvard University Press.

Vajarintarangoon, K., Bunkanan, P., Deelon, S., Poldech, S., \& Thauyngam, K. (2019). The Development process PLC competencies for school administrators in Buriram Province. International Education Studies, 12(6), 148-154. https://doi.org/10.5539/ies.v12n6p148

Vygotsky, L. S. (1987). The collected works of LS Vygotsky: The fundamentals of defectology (Vol. 2). New York: Springer Science \& Business Media.

Wenger, E. (1998). Communities of practice: Learning, meaning, and identity. Cambridge: Cambridge University Press. https://doi.org/10.1017/CBO9780511803932

\section{Copyright Disclaimer}

Copyright for this article is retained by the author(s), with first publication rights granted to the journal.

This is an open-access article distributed under the terms and conditions of the Creative Commons Attribution license (http://creativecommons.org/licenses/by/3.0/). 